\title{
TRANSFORM: a novel study design to evaluate the effect of everolimus on long-term outcomes after kidney transplantation
}

This article was published in the following Dove Press journal:

Open Access Journal of Clinical Trials

10 June 2014

Number of times this article has been viewed

\author{
Julio Pascual' \\ Titte R Srinivas ${ }^{2}$ \\ Steven Chadban ${ }^{3}$ \\ Franco Citterio ${ }^{4}$ \\ Federico Oppenheimer ${ }^{5}$ \\ Helio Tedesco 6 \\ Mitchell L Henry ${ }^{7}$ \\ Christophe Legendre ${ }^{8}$ \\ Yoshihiko Watarai ${ }^{9}$ \\ Claudia Sommerer ${ }^{10}$ \\ Po-Chang Lee"l \\ J Mark Hexham ${ }^{12}$ \\ Gaohong Dong ${ }^{12}$ \\ Peter Bernhardt ${ }^{13}$ \\ Flavio Vincenti ${ }^{14}$
}

'Nephrology Department, Hospital del Mar, Barcelona, Spain; ${ }^{2}$ Division of Nephrology, Medical University of South Carolina, Mt Pleasant, SC. USA; ${ }^{3}$ Department of Transplantation, Royal Prince Alfred Hospital, Camperdown, NSW, Australia; ${ }^{4}$ Centro Trapianti d'Organo Istituto di

Clinica Chirurgica, Università Cattolica del Sacro Cuore, Policlinico Universitario A Gemelli, Rome, Italy; ${ }^{5}$ Renal Transplant Unit, Hospital Clínic de Barcelona, Barcelona, Spain; ' $\mathrm{Nephrology}$ Division, Hospital do Rim, UNIFESP, São Paulo, Brazil;

${ }^{7}$ The Comprehensive Transplant Center, The Ohio State University, Wexner Medical Center, Columbus, OH, USA; ${ }^{8}$ Service de Transplantation Adultes, Université Paris Descartes and Hôpital Necker, Paris, France; ' Department of Transplant Surgery, Nagoya Daini Red Cross Hospital, Nagoya City, Aich, Japan; ${ }^{10}$ Medizinische Klinik, Sektion Nephrologie, Universitätsklinikum Heidelberg, Heidelberg, Germany; "Medical College, National Cheng Kung University, Tainan City, Taiwan; ${ }^{12}$ Biometrics and Statistical Science, Novartis Pharmaceuticals, East Hanover, NJ, USA; ${ }^{13}$ Research and Development, Novartis Pharma AG, Basel, Switzerland; ${ }^{14}$ Kidney Transplant Service, University of California San Francisco, San Francisco, CA, USA

Correspondence: Julio Pascual Nephrology Department, Hospital del Mar, Universitat Autónoma Barcelona, Passeig Maritim 25-2908003 Barcelona, Spain

Tel +34932483162

Email julpascual@gmail.com
Abstract: Two well defined, modifiable risk factors for kidney allograft failure are acute rejection and poor graft function at one year post-transplant. Regulatory bodies and expert panels in the USA and Europe have recognized that both acute rejection and one-year graft function should be assessed when evaluating immunosuppressive regimens. TRANSFORM (Clinicaltrials.gov NCT01950819) is one of the first trials to adopt this approach and the first that applies a novel combined clinically meaningful endpoint to take the first step towards changing the paradigm for immunosuppression in kidney transplant patients. Everolimus with reduced-exposure calcineurin inhibitor $(\mathrm{CNI})$ therapy is a strategy designed to reduce the risk of chronic nephrotoxicity and other dose-dependent complications associated with $\mathrm{CNI}$ therapy. In TRANSFORM, de novo kidney transplant patients are randomized to everolimus with reduced-exposure CNI, or mycophenolic acid with standard-exposure CNI, both with induction therapy and maintenance steroids. The primary endpoint is a composite of treated biopsy-proven acute rejection or estimated glomerular filtration rate $<50 \mathrm{~mL} / \mathrm{min} / 1.73 \mathrm{~m}^{2}$ at month 12 post-transplant, which is expected to be sensitive both to the effects of acute and chronic allograft rejection and nephrotoxic side effects of immunosuppressive therapies. The construct of this endpoint allows the integration of a continuous outcome (graft function) with a logistic outcome (rejection). The trial uses a randomized, multicenter, open-label, two-arm design. After completion of a 2-year core study, patients enter a further 3-year prospective observational study. By capturing follow-up to 5 years, TRANSFORM will provide substantial data on the incidence of graft loss, graft dysfunction, cancer, cardiovascular events, and other patient-relevant outcomes. TRANSFORM will determine whether de novo CNI reduction with an everolimus-based regimen achieves short-term outcomes compared with standard CNI. As the largest clinical trial undertaken to date in kidney transplantation, recruiting more than 2,000 patients, and with extended follow-up to 5 years, TRANSFORM will provide critical data required to help maximize long-term outcomes.

Keywords: mTOR inhibitor, calcineurin inhibitor, reduced exposure

\section{Introduction}

\section{Current challenges for long-term outcomes after kidney transplantation}

Marked improvements in acute rejection rates and graft survival during the first year after kidney transplantation have not been matched by a reduced rate of long-term graft loss. ${ }^{1}$ One year after transplantation, over $90 \%$ of deceased-donor grafts and $97 \%$ of living-donor grafts are functioning. ${ }^{1-3}$ However, by 5 years post-transplant, up to one in four patients has returned to dialysis, ${ }^{1,2,4}$ and half of all grafts fail within 10 years. ${ }^{1,2}$ 
Large-scale multivariable analyses have identified predictive factors for long-term graft loss following kidney transplantation. ${ }^{4,5-10}$ Many factors are entirely or largely nonmodifiable, such as recipient age, type of donor, cold ischemia time, delayed graft function, and concomitant illnesses, such as diabetes mellitus and coronary artery disease. , $6-8,11,12^{-1}$ Acute rejection, while occurring less frequently than in the past, ${ }^{8,9}$ remains a major risk factor associated with increased risk of graft loss, ranging from $15 \%$ to $70 \% .^{6-9}$ The magnitude of the association varies depending on the type and timing of rejection, with late rejection ${ }^{9}$ and antibody-mediated rejection ${ }^{5}$ being particularly hazardous for graft survival.

Graft function during the first year post-transplant is another clear predictor of long-term graft survival., ${ }^{4,910,13-17}$ A recent systematic review of the literature confirmed that 12-month estimated glomerular filtration rate (eGFR) was consistently and significantly associated with an increased risk of death-censored graft loss on multivariate analysis. ${ }^{18}$ As might be expected, patients with severe renal dysfunction at 12 months (chronic kidney disease stage 4; $15-29 \mathrm{~mL} / \mathrm{min} / 1.73 \mathrm{~m}^{2}$ ) show more than a four-fold increase in risk of graft loss compared with chronic kidney disease stage $2\left(60-89 \mathrm{~mL} / \mathrm{min} / 1.73 \mathrm{~m}^{2}\right) .{ }^{15}$ However, even those with moderate renal impairment (eGFR $45-59 \mathrm{~mL} / \mathrm{min} / 1.73 \mathrm{~m}^{2}$ ) are at increased risk of subsequent graft failure compared with patients with better renal function. ${ }^{15}$ All-cause mortality also increases as 12-month eGFR declines, although the magnitude of the association is less marked than for death-censored graft failure $^{18}$ (Table 1). Thus, eGFR at one year post-transplant may represent a surrogate for long-term outcomes. However, although an association between eGFR at one year and subsequent graft loss is undisputed, the predictive utility of eGFR alone for long-term outcomes in specific patients is relatively limited. ${ }^{18,22}$ This lack of predictive utility could be anticipated, given that there are many factors that influence graft and patient survival after kidney transplantation.

Assessment of graft function alone thus appears inadequate to predict long-term outcomes. When assessing the effect of immunosuppressive regimens on long-term outcomes, it would therefore be highly relevant to include both the rate of acute rejection and graft function in the first year after kidney transplantation, both of which are influenced by choice of immunosuppressive therapy. The importance of assessing preservation of graft function, in addition to avoiding rejection and improving long-term survival, was recognized at a public workshop organized by the US Food and Drug Administration in $2012^{23}$ and by the European Medicines Agency. ${ }^{24}$

The ongoing TRANSFORM (Advancing renal TRANSplant eFficacy and safety Outcomes with an

Table I Association between cut-off points for eGFR at month 12 and subsequent death-censored kidney graft loss or mortality on multivariate analysis

\begin{tabular}{|c|c|c|c|c|c|c|c|}
\hline \multirow[t]{2}{*}{ Study } & \multirow[t]{2}{*}{$\mathbf{n}$} & \multirow{2}{*}{$\begin{array}{l}\text { Follow-up (time } \\
\text { post-transplant) }\end{array}$} & \multirow{2}{*}{$\begin{array}{l}\text { eGFR at month } 12 \\
\left(\mathrm{~mL} / \mathrm{min} / 1.73 \mathrm{~m}^{2}\right)^{\mathrm{a}}\end{array}$} & \multicolumn{2}{|c|}{ Death-censored graft loss } & \multicolumn{2}{|l|}{ Mortality } \\
\hline & & & & HR (95\% Cl) & $P$-value & HR (95\% Cl) & $P$-value \\
\hline \multirow[t]{6}{*}{ Kasiske et al ${ }^{15}$} & $|3,67|$ & 10 years & $\geq 90$ & $1.04(0.73,1.48)$ & 0.8 & $1.61(1.22,21.4)$ & $<0.001$ \\
\hline & & & $60-89$ & Reference & Reference & Reference & Reference \\
\hline & & & $45-59$ & $1.35(1.08,1.44)$ & 0.003 & $0.98(0.84,1.13)$ & 0.8 \\
\hline & & & $30-44$ & $2.0 \mathrm{I}(1.75,2.32)$ & $<0.001$ & $1.07(0.92,1.25)$ & 0.4 \\
\hline & & & $15-29$ & $4.63(3.95,5.44)$ & $<0.001$ & $1.58(1.30,1.91)$ & $<0.00 \mathrm{I}$ \\
\hline & & & $<15$ & $26.69(20.85,34.18)$ & $<0.001$ & $2.80(1.51,5.17)$ & 0.001 \\
\hline \multirow[t]{3}{*}{ Remport et $\mathrm{al}^{20}$} & 985 & 5 years & $\geq 60$ & Reference $^{\mathrm{b}}$ & Reference & Reference & Reference \\
\hline & & & $30-59$ & I.5I $(0.77,2.90)^{\mathrm{b}}$ & 0.233 & $0.91(0.56,1.47)$ & 0.688 \\
\hline & & & $<30$ & $3.63(1.67,7.88)^{b}$ & 0.001 & $2.58(1.49,4.80)$ & 0.001 \\
\hline \multirow[t]{8}{*}{ Schnitzler et $\mathrm{a}^{21}$} & 38,015 & 3 years & $\geq 60$ & Reference & Reference & Reference & Reference \\
\hline & & & $45-59$ & I.31 & $<0.001$ & 1.09 & $<0.001$ \\
\hline & & & $30-44$ & 2.49 & $<0.001$ & $\mathrm{I} .34$ & $<0.001$ \\
\hline & & & $15-29$ & 7.22 & $<0.001$ & 2.33 & $<0.001$ \\
\hline & & 4-7 years & $\geq 60$ & Reference & Reference & Reference & Reference \\
\hline & & & $45-59$ & 1.28 & $<0.001$ & 1.09 & NS \\
\hline & & & $30-44$ & 1.80 & $<0.001$ & 1.34 & $<0.001$ \\
\hline & & & $15-29$ & 3.35 & $<0.001$ & 2.33 & $<0.001$ \\
\hline \multirow[t]{2}{*}{ Wu et a $\left.\right|^{17}$} & 1,062 & Mean 94 months & $\geq 45$ & Reference & Reference & - & - \\
\hline & & & $<45$ & $2.65(I .62,4.3 \mathrm{I})$ & $<0.001$ & & \\
\hline
\end{tabular}

Notes: aMDRD4 (four-variable Modification of Diet in Renal Disease) formula; 19 breturn to dialysis.

Abbreviations: $\mathrm{Cl}$, confidence interval; eGFR, estimated glomerular filtration; HR, hazard ratio; NS, not statistically significant. 
eveRoliMus-based regimen [ClinicalTrials.gov identifier NCT01950819]) trial is the first study in kidney transplantation to evaluate both immunosuppressive efficacy and graft function in a single combined primary endpoint. The rationale and design of the trial are considered here.

\section{Everolimus: an opportunity to improve long-term outcomes}

The mammalian target of rapamycin (mTOR) inhibitor everolimus offers the prospect of addressing some of the leading causes of long-term graft deterioration and death. ${ }^{25,26}$

\section{Calcineurin inhibitor reduction}

A key role for everolimus is to reduce exposure to calcineurin inhibitor (CNI) agents. CNI therapy exerts a well-recognized, dose-dependent, deleterious effect on graft function by inducing progressive nonreversible nephrotoxicity. ${ }^{27,28}$ A series of randomized trials in de novo kidney transplant patients has demonstrated consistently that immunosuppression with everolimus and a reduced-exposure CNI regimen maintains efficacy. ${ }^{29-33}$ By facilitating as much as a $60 \%$ reduction in CNI exposure, ${ }^{34}$ everolimus reduces the potential for chronic CNI-related nephrotoxic effects. By reducing CNI exposure, use of everolimus can also lower the risk of long-term cardiovascular complications of CNI therapy, such as new-onset diabetes mellitus and hypertension. ${ }^{35}$

\section{Nonimmunosuppressive effects}

The indirect advantages of CNI reduction are complemented by the pleiotropic effect and other nonimmunosuppressive actions of everolimus. In terms of cardiovascular function, experimental evidence indicates that mTOR inhibition can lead to regression of cardiac hypertrophy, ${ }^{36,37}$ and a remodeling benefit has been shown in kidney transplant patients receiving everolimus therapy. ${ }^{38,39}$ mTOR inhibitors inhibit atherosclerotic plaque development and rupture in animal models, ${ }^{40}$ consistent with evidence showing that their antiproliferative effect ameliorates the progression of transplant vasculopathy in heart transplant patients. ${ }^{41,42}$ Further, preliminary data suggest that mTOR inhibitors may attenuate the development of arterial stiffness, ${ }^{43,44}$ a known risk factor for post-transplant cardiovascular events. ${ }^{45}$

Additionally, the pleiotropic effects of everolimus raise the possibility that the rate of post-transplant malignancy, a leading cause of late mortality after kidney transplantation, ${ }^{46,47}$ may be reduced. ${ }^{48} \mathrm{~A}$ randomized, double-blind trial demonstrated significantly better progression-free survival in patients with metastatic renal cell carcinoma who received everolimus versus placebo ${ }^{49}$ and in solid organ transplant patients. ${ }^{50,51}$ Everolimus is licensed for the treatment of advanced renal carcinoma and advanced breast cancer, and trials are currently investigating its benefit in other types of malignancy.

Lastly, compared with standard CNI-based therapy, everolimus also appears to reduce the incidence of viral infections, a major cause of mortality after kidney transplantation. ${ }^{46,47,52}$ Cytomegalovirus (CMV) and BK virus infection are also known risk factors for graft loss. ${ }^{53}$ There is convincing evidence that the incidence of viral infections (notably CMV and BK virus) is significantly lower in everolimus-treated kidney transplant patients versus those receiving a standard CNI-based regimen. ${ }^{54,55}$ Moreover, everolimus retains its antiviral properties when combined with CNI therapy. This beneficial effect may be maximized by using everolimus immediately post-transplant, since CMV infection usually develops within the first months.

\section{TRANSFORM: a modern approach to assessing outcomes}

A large number of randomized, controlled trials have assessed the efficacy and safety of everolimus in solid organ transplantation. ${ }^{56}$ In trials of everolimus with reduced-exposure CNI therapy in de novo kidney transplants, the primary endpoint has either assessed efficacy (defined as the incidence of biopsy-proven acute rejection [BPAR] or a combined efficacy endpoint $)^{31,32}$ or renal function based on eGFR. ${ }^{29,30}$

The TRANSFORM trial, for the first time, combines the stochastic outcome of rejection with a continuous measure of graft function (eGFR) in a single, clinically relevant composite primary endpoint. It takes into account both the need to effectively prevent graft rejection and maintain good graft function when comparing immunosuppressive regimens. ${ }^{23}$ The trial will recruit over 2,000 patients, making it the largest randomized study ever undertaken in kidney transplantation. Patients will be recruited in over 40 countries in all five continents. Patients will be followed to 5 years after kidney transplantation to assess long-term outcomes.

\section{Materials and methods Study design}

TRANSFORM is a randomized, multicenter, open-label, two-arm study (Figure 1). After completion of the 2-year core study, patients enter a further 3-year observational follow-up study. Patients are randomized at the time of transplantation to receive either everolimus with reduced-exposure CNI therapy, or mycophenolic acid with standard-exposure CNI, both with 


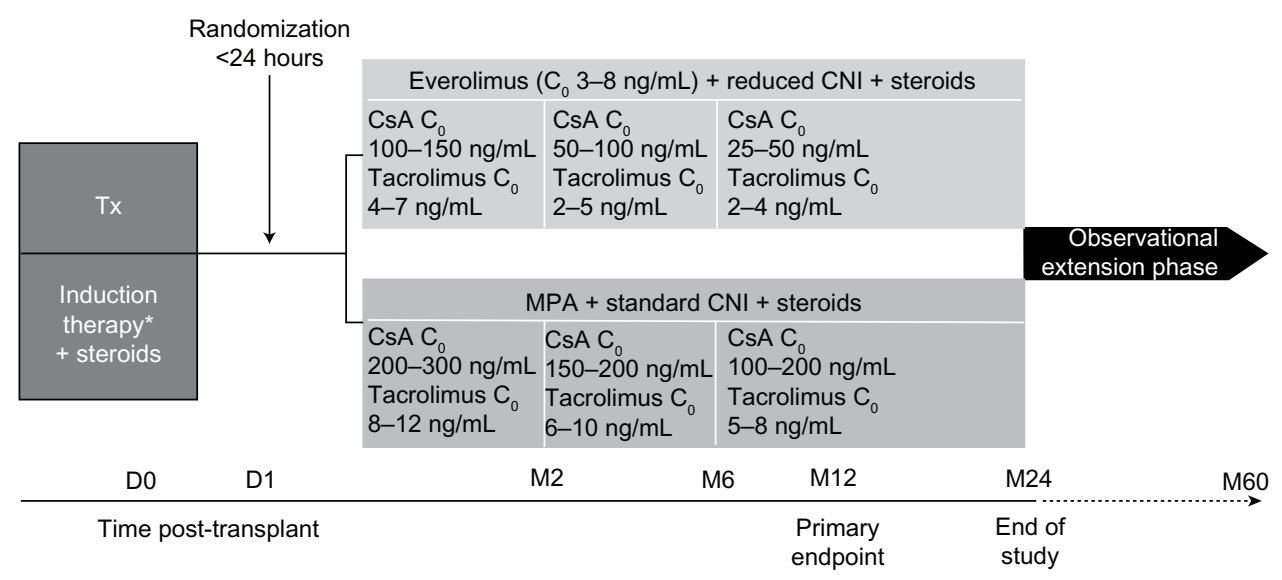

Figure I TRANSFORM study design.

Notes: Stratified for CNI (CsA or tacrolimus) and donor type (living, deceased standard criteria or deceased expanded criteria). *Basiliximab or antithymocyte globulin. Abbreviations: CNI, calcineurin inhibitor; CsA, cyclosporine; MPA, mycophenolic acid; TRANSFORM, Advancing renal TRANSplant eFficacy and safety Outcomes with an eveRoliMus-based regimen; Tx, transplantation.

induction therapy and maintenance steroids. The protocol and the proposed informed consent form are currently being reviewed and approved by a properly constituted institutional review board or independent ethics committee at each center. Written informed consent is obtained from all patients. The trial is conducted in accordance with the ethical principles laid down in the Declaration of Helsinki.

\section{Selection of primary endpoint}

Of the various renal parameters that have been investigated as markers for graft outcomes, including eGFR, slope of eGFR evolution, serum creatinine and proteinuria, eGFR at month 12 has been most thoroughly explored and has consistently been found to be associated with graft loss. ${ }^{18}$ Several studies have examined cut-off points for the association between eGFR at 12 months and long-term graft survival (up to 10 years), generally based on stages 1-5 of chronic kidney disease (Table 1). The relationship is nonlinear, ${ }^{15,57}$ with a dramatic increase in risk of graft loss with severe renal dysfunction, ${ }^{15}$ but even when 12-month eGFR is in the range of $45-59 \mathrm{~mL} / \mathrm{min} / 1.73 \mathrm{~m}^{2}$ (chronic kidney disease stage $3 \mathrm{~A}$ ), patients have a significantly increased risk of graft loss compared with patients with better renal function.

A well-functioning graft would be expected to have an $\mathrm{eGFR} \geq 60 \mathrm{~mL} / \mathrm{min} / 1.73 \mathrm{~m}^{2}{ }^{58} \mathrm{An}$ eGFR of $50 \mathrm{~mL} / \mathrm{min} / 1.73 \mathrm{~m}^{2}$ represents a moderate level of renal dysfunction according to the chronic kidney disease staging criteria. ${ }^{15,21}$ A retrospective analysis of data from the recent A2309 multicenter trial in which de novo kidney transplantation patients were randomized to everolimus with reduced-dose CNI versus enteric-coated mycophenolate sodium with standard $\mathrm{CNI}^{31,34}$ examined different cut-off points for eGFR at 12 months post-transplant to differentiate between the two treatment groups ${ }^{57}$ Results showed that the proportion of patients with low eGFR using a cut-off point of $50 \mathrm{~mL} / \mathrm{min} / 1.73 \mathrm{~m}^{2}$ was significantly lower in the everolimus treatment group $(38.2 \%$ versus $50.5 \%$; difference $-12.3 \%$ with a $95 \%$ confidence interval of $-20.6 \%,-4.1 \%$ ).

Accordingly, a cut-off point of $50 \mathrm{~mL} / \mathrm{min} / 1.73 \mathrm{~m}^{2}$ for eGFR at month 12 post-transplant was selected as a surrogate for good graft function in the TRANSFORM study. Studies have shown that patients with BPAR have significantly lower renal function than those without BPAR, while patients with less severe BPAR tended to have better renal function compared with those who experience more severe BPAR. ${ }^{59,60}$ It is expected that evolution of renal function will show a negative correlation with treated BPAR in the TRANSFORM study. Therefore, the two components (treated BPAR and eGFR $<50 \mathrm{~mL} / \mathrm{min} / 1.73 \mathrm{~m}^{2}$ ) will show the same trend and account for the effects of both acute and chronic allograft rejection and the nephrotoxic side effects of immunosuppressive therapies. The four-variable Modification of Diet in Renal Disease (MDRD4) formula ${ }^{19}$ was selected for estimation of GFR. MDRD4 is a formula that is widely employed in clinical trials of transplant patients, and has been widely used in trials investigating the effect of different eGFR levels on patient outcomes (Table 1). No equation for estimation of GFR appears inferior or superior for predicting graft failure or mortality following kidney transplantation. ${ }^{22}$

The renal cut-off point of eGFR $<50 \mathrm{~mL} / \mathrm{min} / 1.73 \mathrm{~m}^{2}$ was combined with occurrence of treated BPAR, a widely accepted measure of immunosuppressive efficacy in solid 
organ transplantation. It is well established that treated BPAR is also an important predictive factor for long-term graft failure after renal transplantation, with severity of acute rejection showing a statistical association with nonresponsiveness to antirejection treatment and increased risk of graft failure. ${ }^{59,61}$ Treated BPAR was defined as receipt of antirejection treatment and histological diagnosis of acute rejection according to Banff 2009 criteria. ${ }^{62}$ This composite endpoint represents a clinically meaningful approach to discriminate between immunosuppressive regimens in renal transplantation.

\section{Secondary objectives}

The key secondary objective of the TRANSFORM trial is to evaluate the two treatment groups with respect to a composite efficacy failure endpoint comprising treated BPAR, graft loss, or death (see Table 2), consistent with recommendations from the European Medicines Agency. ${ }^{24}$ Other secondary objectives include assessment of individual components of this composite failure endpoint, and evolution of renal function via a slope analysis. Safety objectives include standard assessments of adverse events and serious adverse events, and specific objectives relating to this study population that are of concern to transplant physicians, including comorbidities such as cardiovascular complications, malignancies, viral infections, and renal failure.

Exploratory objectives include evaluation of the incidence of donor-specific antibodies by treatment group and in relation to acute rejection in a subset of patients at participating centers. The clinical significance of donor-specific antibodies, specifically whether or not they contribute to antibody-mediated rejection, is not fully elucidated and is currently a topic of considerable interest to transplant physicians. Prospectively collected data on donor-specific antibody status in the TRANSFORM substudy will permit a thorough characterization of donor-specific antibodies in antibody-mediated rejection and a comparison of the effect of the two treatment regimens on de novo donor-specific antibody development post-transplant.

\section{Study population}

The study population comprises de novo adult kidney transplant patients. The study has broad eligibility criteria and, in general terms, enrolls patients unless they are sensitized or have received a graft from a donor after cardiac death. Specific key inclusion and exclusion criteria are shown in Table 3. Patients can be recipients of a graft from a living donor or a deceased donor, based on standard or extended criteria. Patients who had undergone a previous kidney transplant could be enrolled if the first graft had not been lost due to immunological reasons. The eligibility criteria exclude patients at high risk of rejection (based on local practice for assessment of antidonor reactivity such as high panel reactive antibodies or presence of pre-existing donorspecific antibody), if they have lost a previous kidney transplant due to immunological causes, or have cold ischemia time $>30$ hours. Thus, the study population is at moderate immunological risk. The eligibility criteria did not include any specifications relating to baseline proteinuria or the risk of developing proteinuria post-transplant.

\section{Randomization and study treatment}

Patients are randomized within 24 hours of completion of the transplant procedure. Randomization is stratified within treatment groups by donor type (living, deceased standard criteria, or deceased expanded criteria) and by the type of CNI administered (cyclosporine or tacrolimus). The overall study population will contain no less than $50 \%$ of living-donor recipients, and patients receiving cyclosporine will comprise no more than $20 \%$ of the population.

The immunosuppressive regimens used in the study are widely used in clinical practice. Investigators may use either CNI therapy, with or without steroids, and either of the two most frequently administered induction therapies can be given.

All patients will receive induction therapy with basiliximab (two $20 \mathrm{mg}$ doses, administered on days 0 and 4 ) or rabbit antithymocyte globulin $(1.5 \mathrm{mg} / \mathrm{kg} /$ day with a total dosage $\leq 6 \mathrm{mg} / \mathrm{kg})$. Since induction therapy is initiated before randomization, the allocated treatment arm will not bias the decision as to whether to administer basiliximab or antithymocyte globulin. Treatment with CNI, mycophenolic acid, and/or steroids may be started prior to transplant according to center practice but must be applied consistently to all subjects at a given center.

For patients randomized to the everolimus group, the initial dose of everolimus will depend on the concomitant CNI (tacrolimus or cyclosporine) because of pharmacokinetic interactions. ${ }^{63}$ With concomitant tacrolimus, the starting dose is $3.0 \mathrm{mg}$ /day, compared with $1.5 \mathrm{mg}$ /day in patients receiving concomitant cyclosporine. In either case, the dose is then adjusted to target a locally determined everolimus trough concentration $\left(\mathrm{C}_{0}\right)$ of $3-8 \mathrm{ng} / \mathrm{mL}$ throughout the study. $\mathrm{CNI}$ dose is adjusted to maintain the target $\mathrm{C}_{0}$ concentration ranges shown in Figure 1.

In the mycophenolic acid treatment arm (the control group), the initial mycophenolic acid dose is enteric-coated mycophenolate sodium $1.44 \mathrm{~g} /$ day or $2.0 \mathrm{~g} /$ day for mycophenolate mofetil. For control patients receiving tacrolimus, the dose should be 
Table 2 Objectives of the TRANSFORM study

\begin{tabular}{|c|c|}
\hline Primary objective & $\begin{array}{l}\text { To evaluate the effect of everolimus with reduced-exposure CNI versus MPA with standard-exposure CNI on the } \\
\text { composite of treated BPAR or eGFR }<50 \mathrm{~mL} / \mathrm{min} / 1.73 \mathrm{~m}^{2} \text { (MDRD4) at month } 12 \text { post-transplant }\end{array}$ \\
\hline Key secondary objective & $\begin{array}{l}\text { To evaluate everolimus with reduced-exposure } \mathrm{CNI} \text { versus MPA plus standard-exposure } \mathrm{CNI} \text { with respect to the } \\
\text { composite efficacy failure rate of treated BPAR, graft loss or death at month } 12 \text { post-transplant }\end{array}$ \\
\hline \multirow[t]{23}{*}{ Other secondary objectives } & To evaluate, by treatment group: \\
\hline & Composite endpoint of treated BPAR, graft loss, death or eGFR $<50 \mathrm{~mL} / \mathrm{min} / \mathrm{I} .73 \mathrm{~m}^{2}$ at months 12 and 24 \\
\hline & Composite endpoint of treated BPAR, graft loss or death at month 24 \\
\hline & Composite endpoint of treated BPAR, graft loss, death, or loss to follow-up at months 12 and 24 \\
\hline & Composite endpoint of graft loss or death at months 12 and 24 \\
\hline & Death, graft loss, treated BPAR, BPAR, treated acute rejection, acute rejection, or humoral rejection at months 12 and 24 \\
\hline & Incidence of composite endpoint of treated BPAR or eGFR $<50 \mathrm{~mL} / \mathrm{min} / 1.73 \mathrm{~m}^{2}$ (MDRD4) among compliant subjects \\
\hline & Incidence of composite endpoint of treated BPAR or eGFR $<50 \mathrm{~mL} / \mathrm{min} / \mathrm{I} .73 \mathrm{~m}^{2}$ (MDRD4) among subgroups \\
\hline & Incidence of treated BPAR (excluding grade IA rejections) or eGFR $<50 \mathrm{~mL} / \mathrm{min} / \mathrm{I} .73 \mathrm{~m}^{2}$ \\
\hline & Incidence of treated BPAR by severity and time to event \\
\hline & Incidence of treated BPAR excluding grade IA rejections \\
\hline & Composite endpoint of treated BPAR or eGFR $<50 \mathrm{~mL} / \mathrm{min} / 1.73 \mathrm{~m}^{2}$ (MDRD4) at month 24 \\
\hline & eGFR $<50 \mathrm{~mL} / \mathrm{min} / 1.73 \mathrm{~m}^{2}$ at months 12 and 24 \\
\hline & Renal function (eGFR) at months 12 and 24 \\
\hline & Evolution of renal function (eGFR) over time by slope analysis \\
\hline & Change in renal allograft function from month I (eGFR) at months 12 and 24 \\
\hline & Renal function assessed by cystatin C-based and alternative formulae at months 12 and 24 \\
\hline & Adverse events, serious adverse events, and adverse events leading to study regimen discontinuation \\
\hline & Cytomegalovirus infection, BK virus infection, new onset diabetes mellitus, chronic kidney disease with associated \\
\hline & proteinuria, and $\mathrm{CNI}$-associated adverse events \\
\hline & Urinary protein and albumin excretion estimated by urinary protein/creatinine and urinary albumin/creatinine ratios \\
\hline & Major cardiovascular events \\
\hline & Malignancies \\
\hline \multirow[t]{3}{*}{ Exploratory objectives } & $\begin{array}{l}\text { To explore the incidence of DSA by treatment group, and in relation to acute rejection, in a subset of patients at } \\
\text { participating centers }\end{array}$ \\
\hline & $\begin{array}{l}\text { To explore the development of chronic allograft nephropathy/interstitial fibrosis-tubular atrophy on protocol renal } \\
\text { biopsy in a subset of patients at participating centers }\end{array}$ \\
\hline & To support codevelopment and validation of everolimus assays or diagnostic systems at selected centers \\
\hline
\end{tabular}

Abbreviations: BPAR, biopsy-proven acute rejection; CNI, calcineurin inhibitor; DSA, donor specific antibody; eGFR, estimated glomerular filtration rate; MDRD4, fourvariable Modification of Diet in Renal Disease; MPA, mycophenolic acid; TRANSFORM, Advancing renal TRANSplant eFficacy and safety Outcomes with an eveRoliMus-based regimen.

reduced after week 2 to enteric-coated mycophenolate sodium $1.08 \mathrm{~g} /$ day or mycophenolate mofetil $1.5 \mathrm{~g} /$ day, but should remain unchanged in control patients receiving cyclosporine. The dose of tacrolimus or cyclosporine is adjusted according to the target ranges shown in Figure 1. The minimum dose of tacrolimus is $0.5 \mathrm{mg}$ twice daily, and the minimum dose of cyclosporine is $25 \mathrm{mg}$ twice daily.

\section{Concomitant medication}

Pre-emptive CMV therapy and/or prophylaxis for at least 6 months post-transplant is recommended for all cases where the donor is CMV-positive and the recipient is CMV-negative, and should be considered for all CMV-positive recipients. All patients will receive trimethoprim-sulfamethoxazole as prophylaxis for Pneumocystis jirovecii pneumonia for at least 6 months after transplantation. Lipid-lowering medications are to be administered according to guidelines and local practice.

\section{Statistical analysis}

For the primary endpoint (treated BPAR or eGFR [MDRD4] $<50 \mathrm{~mL} / \mathrm{min} / 1.73 \mathrm{~m}^{2}$ at month 12 ), treatment by CNI interaction will be assessed using a logistic regression model. If the interaction is not significant at the level of 0.10 (ie, the effect of treatment is similar for tacrolimus and cyclosporine), then the primary analysis will be based on pooled CNI data in each treatment group. If this test shows significantly different event rates for tacrolimus versus cyclosporine, then testing will be performed for the two CNI therapies separately, with the tacrolimus subgroup being considered primary and the cyclosporine subgroup being considered exploratory due to the expected smaller sample size. Event rates will be compared between groups using a hierarchical testing strategy: noninferiority of the everolimus group versus the mycophenolic acid group for the primary endpoint using a 10\% noninferiority margin; noninferiority of the everolimus group versus the mycophenolic acid group for the key secondary endpoint (the composite of treated BPAR, graft loss, or death) with 
Table 3 Key inclusion and exclusion criteria for the TRANSFORM study

\begin{tabular}{|c|c|}
\hline Key inclusion criteria & Key exclusion criteria \\
\hline $\begin{array}{l}\text { Male or female subjects } \geq 18 \text { years } \\
\text { Randomized }<24 \text { hours after transplant surgery } \\
\text { Cold ischemia time }<30 \text { hours } \\
\text { Recipient of a primary (or secondary, if first graft was not lost } \\
\text { due to immunological reasons) kidney transplant from a deceased } \\
\text { heart beating donor, living unrelated donor, living related } \\
\text { non-human leukocyte antigen identical donor, or an expanded } \\
\text { criteria donor }^{\mathrm{a}}\end{array}$ & $\begin{array}{l}\text { Use of other investigational drugs at the time of enrollment, or within } 30 \text { days } \\
\text { or five half-lives of enrollment, whichever is longer (except for dialysis-related } \\
\text { drugs which are not expected to interact with the study regimens) } \\
\text { Multiorgan transplant recipient } \\
\text { ABO incompatible allograft or complement-dependent lymphocytotoxic } \\
\text { crossmatch positive transplant } \\
\text { High immunological risk for rejection } \\
\text { Recipient or donor positive for HIV, hepatitis B surface antigen or hepatitis C } \\
\text { Body mass index }>35 \mathrm{~kg} / \mathrm{m}^{2} \\
\text { Severe systemic infection (current or within } 2 \text { weeks prior to randomization) } \\
\text { Requirement for systemic anticoagulation that cannot be temporarily } \\
\text { interrupted and which would preclude renal biopsy } \\
\text { History of malignancy of any organ system (other than localized basal } \\
\text { cell carcinoma of the skin), treated or untreated, within the past } 5 \text { years, } \\
\text { regardless of whether there is evidence of local recurrence or metastases } \\
\text { Severe restrictive or obstructive pulmonary disorders } \\
\text { Severe uncontrolled hypercholesterolemia or hypertriglyceridemia } \\
\text { White blood cell count } \leq 2,000 / m^{3} \text { or platelet count } \leq 50,000 / \mathrm{mm}^{3} \\
\text { Pregnant or nursing (lactating) women } \\
\text { Women of child-bearing potential, unless they are using effective methods of } \\
\text { contraception during dosing of study treatment }\end{array}$ \\
\hline
\end{tabular}

Notes: a Defined as brain-dead donor aged $>60$ years or donor aged $>50$ years with two of the following: history of hypertension, terminal serum creatinine $\geq 1.5 \mathrm{mg} / \mathrm{dL}$ ( $132 \mu \mathrm{mol} / \mathrm{L}$ ) or death resulting from cerebrovascular accident; bas determined by local practice for assessment of antidonor reactivity, eg, high panel reactive antibodies, presence of pre-existing donor specific antigen.

Abbreviation: TRANSFORM, Advancing renal TRANSplant efficacy and safety Outcomes with an eveRoliMus-based regimen.

a $10 \%$ noninferiority margin; and superiority of the everolimus group to the mycophenolic acid group based on the primary endpoint. Missing eGFR values will be handled as follows: subjects who lose their grafts will be assigned a value of zero for eGFR at month 12; for other subjects with missing eGFR data, including those who die with a functioning graft, eGFR will be imputed using a multiple imputation method under missing at random assumption based on the longitudinal eGFR (MDRD4) data at all available time points and covariates of randomization strata (donor type and CNI), HLA mismatches ( $\leq 3$ versus $>3$ ), and induction. Based on a sample size of 1,020 patients in each treatment arm (2,040 in total), the study will have at least 95\% power to demonstrate noninferiority ( $\alpha=0.025$, one-sided) for the primary endpoint in the overall study population, and in the tacrolimus subgroup, at month 12 .

Supportive analyses for the primary endpoint will include an analysis based on the per-protocol population, and different imputations for missing eGFR values under missing not at random assumption. The incidence rates in the primary endpoint will also be summarized for predefined subgroups based on recipient age, donor characteristics, type of CNI, type of induction, and immunological status, using the Z-test to compare event rates. A logistic regression model will be used to investigate prognostic variables that might have an impact on the primary efficacy endpoint.
Following the intent-to-treat principle, analyses of efficacy and renal function will be based on the full analysis set, comprising all randomized and transplanted subjects who received the study drug. Selected parameters will also be analyzed in the per-protocol population, which will include all patients in the full analysis set who complete the study without any major deviations from protocol procedures. All safety analyses will be performed on the safety set, consisting of all subjects who receive at least one dose of study drug.

\section{Conclusion}

TRANSFORM is the first trial of immunosuppression in kidney transplantation that captures the key surrogate markers of long-term outcomes in a novel single combined primary endpoint. Combining the efficacy marker of treated BPAR with the renal function parameter of eGFR at month 12 as the primary endpoint is designed to assess optimal immunosuppression, ie, adequate to avoid rejection without overexposure and the associated risk of nephrotoxicity, in order to maximize graft preservation. The trial is also the largest undertaken to date in kidney transplantation, recruiting a population of more than 1,000 patients per arm, and will follow patients to 5 years post-transplant. The scale and duration of the study and its novel primary endpoint mean that TRANSFORM is likely to be regarded as a landmark study in the field. 


\section{Disclosure}

JP has received consulting honoraria from Novartis and travel grants from Novartis and Astellas, and his institution has received research grants from Novartis, Astellas, and Roche. TRS has received consulting honoraria grant support from Novartis and grants from Astellas, Bristol Myers Squibb, and Novartis. SC has received research funding, travel support, or consulting honoraria from Novartis, Astellas, Alexion Pharmaceuticals, Amgen, and Roche. FC has received consulting honoraria and travel grants from Novartis, Astellas, Pfizer, and Bristol Myers Squibb. FO has received consulting honoraria and travel grants from Novartis, Astellas, Pfizer, Bristol Myers Squibb, and Roche, and his institution has received research grants from Novartis and Astellas. HT has received consulting honoraria and travel grants from Novartis, Pfizer, Bristol Myers Squibb, and Roche, and his institution has received research grants from Novartis, Pfizer, Bristol Myers Squibb, Roche, Veloxis Pharmaceuticals, and Theraclone. $\mathrm{MH}$ has received consulting honoraria from Novartis. CL has received speaker's honoraria from Alexion and Novartis, and travel grants from Alexion, Novartis, and Amgen. YW has received speaker's honoraria from Novartis, Astellas, Chugai, and Roche, and travel grants from Roche. CS has received travel grants from Novartis and the institution has received research grants from Novartis and Astellas. P-CL has no conflicts of interest to declare. JMH, GD, and PB are employees of Novartis. FV has received research grants from Novartis, Astellas, Genentech, Alexion, and Bristol Myers Squibb. The study is funded by Novartis Pharma AG. We thank Caroline Dunstall who provided medical writing services on behalf of Novartis Pharma AG.

\section{References}

1. US Department of Health and Human Services. Organ Procurement and Transplant Network Annual Data Report 2011. Available from: http://optn.transplant.hrsa.gov/news/newsDetail.asp?id=1589. Accessed April 17, 2014.

2. Gondos A, Döhler B, Brenner H, Opelz G. Kidney graft survival in Europe and the United States: strikingly different long-term outcomes. Transplantation. 2013;95(2):267-274.

3. US Renal Data System. 2012 Atlas of CKD and ESRD. 2012 Annual Data Report. Available from: http://www.usrds.org/atlas12.aspx. Accessed November 18, 2013.

4. Morales JM, Marcén R, del Castillo D, et al. Risk factors for graft loss and mortality after renal transplantation according to recipient age: a prospective multicentre study. Nephrol Dial Transplant. 2012; 27 Suppl 4:iv39-iv46.

5. Dunn TB, Noreen H, Gillingham K, et al. Revisiting traditional risk factors for rejection and graft loss after kidney transplantation. Am J Transplant. 2011;11(10):2132-2143.

6. Øien CM, Reisaeter AV, Leivestad T, Dekker FW, Line PD, Os I. Living donor kidney transplantation: the effects of donor age and gender on shortand long-term outcomes. Transplantation. 2007;83(5):600-606.
7. Quiroga I, McShane P, Koo DD, et al. Major effects of delayed graft function and cold ischaemia time on renal allograft survival. Nephrol Dial Transpl. 2006;21(6):1689-1696.

8. Cole EH, Johnston O, Rose CL, Gill JS. Impact of acute rejection and new-onset diabetes on long-term transplant graft and patient survival. Clin J Am Soc Nephrol. 2008;3(3):814-821.

9. McDonald S, Russ G, Campbell S, Chadban S. Kidney transplant rejection in Australia and New Zealand: relationships between rejection and graft outcome. Am J Transplant. 2007;7(5):1201-1208.

10. Pascual J, Marcén R, Zamora J, et al. Very early serum creatinine as a surrogate marker for graft survival beyond 10 years. J Nephrol. 2009;22(1):90-98.

11. Gore JL, Pham PT, Danovitch GM, et al. Obesity and outcome following renal transplantation. Am J Transplant. 2006;6(2):357-363.

12. Pascual J, Zamora J, Pirsch JD. A systematic review of kidney transplantation from expanded criteria donors. Am J Kidney Dis. 2008;52(3):553-586.

13. National Cholesterol Education Program Expert Panel on Detection, Evaluation, and Treatment of High Blood Cholesterol in Adults (Adult Treatment Panel III): Third Report of the National Cholesterol Education Program (NCEP) Expert Panel on Detection, Evaluation, and Treatment of High Blood Cholesterol in Adults (Adult Treatment Panel III) final report. Circulation. 2002;106(25):3143-3421.

14. Park WD, Larson TS, Griffin MD, Stegall MD. Identification and characterization of kidney transplants with good glomerular filtration rate at 1 year but subsequent progressive loss of renal function. Transplantation. 2012;94(9):931-939.

15. Kasiske BL, Israni AK, Snyder JJ, Skeans MA; Patient Outcomes in Renal Transplantation (PORT) Investigators. The relationship between kidney function and long-term graft survival after kidney transplant. Am J Kidney Dis. 2011;57(3):466-475.

16. Lenihan CR, O'Kelly P, Mohan P, et al. MDRD-estimated GFR at one year post-renal transplant is a predictor of long-term graft function. Ren Fail. 2008;30(4):345-352.

17. Wu J, Li H, Huang $\mathrm{H}$, et al. Slope of changes in renal function in the first year post-transplantation and one-yr estimated glomerular filtration rate together predict long-term renal allograft survival. Clin Transplant. 2010;24(6):862-868.

18. Smith-Palmer J, Kalsekar A, Valentine W. Influence of renal function on long-term graft survival and patient survival in renal transplant recipients. Curr Med Res Opin. 2014;30(2):235-242.

19. Levey AS, Bosch JP, Lewis JB, Greene T, Rogers N, Roth D. A more accurate method to estimate glomerular filtration rate from serum creatinine: a new prediction equation. Ann Intern Med. 1999;130(6):461-470.

20. Remport A, Molnar MZ, Ambrus C, et al. Impaired renal function is associated with mortality in kidney-transplanted patients. Int Urol Nephrol. 2010;42(3):799-809.

21. Schnitzler MA, Johnston K, Axelrod D, Gheorghian A, Lentine KL. Associations of renal function at 1-year after kidney transplantation with subsequent return to dialysis, mortality, and healthcare costs. Transplantation. 2011;91(12):1347-1356.

22. He X, Moore J, Shabir S, et al. Comparison of the predictive performance of eGFR formulae for mortality and graft failure in renal transplant recipients. Transplantation. 2009;87(3):384-392.

23. US Food and Drug Administration. Endpoints in Clinical Trials of Kidney Transplantation: Public Workshop. Available from: http://www. fda.gov/Drugs/NewsEvents/ucm305308.htm. Accessed November 20, 2013.

24. Committee for Medicinal Products for Human Use. European Medicines Agency. Guideline on clinical investigation of immunosuppressants for solid organ transplantation. Available from: http://www.ema.europa. eu/docs/en_GB/document_library/Scientific_guideline/2009/09/ WC500003593.pdf. Accessed November 20, 2013.

25. Campistol JM, de Fijter JW, Nashan B, Holdaas H, Vítko S, Legendre C. Everolimus and long-term outcomes in renal transplantation. Transplantation. 2011;92(Suppl 3):S3-S26. 
26. Holdaas H, Midtvedt K, Åsberg A. A drug safety evaluation of everolimus in kidney transplantation. Expert Opin Drug Saf. 2012;11(6): 1013-1022.

27. Chapman JR. Chronic calcineurin inhibitor nephrotoxicity - lest we forget. Am J Transplant. 2011;11(4):693-697.

28. Ojo A, Held PHJ, Port FK, et al. Chronic renal failure after transplantation of a nonrenal organ. $N$ Engl J Med. 2003;349(10):931-940.

29. Vitko S, Tedesco H, Eris J, et al. Everolimus with optimized cyclosporine dosing in renal transplant recipients: 6-month safety and efficacy results of two randomized studies. Am J Transplant. 2004;4(4):626-635.

30. Chan L, Greenstein S, Hardy MA, et al; CRADUS09 Study Group. Multicenter, randomized study of the use of everolimus with tacrolimus after renal transplantation demonstrates its effectiveness Transplantation. 2008;85(6):821-826.

31. Tedesco Silva H Jr, Cibrik D, Johnston T, et al. Everolimus plus reducedexposure CsA versus mycophenolic acid plus standard-exposure CsA in renal-transplant recipients. Am J Transplant. 2010;10(6) 1401-1413.

32. Albano L, Berthoux F, Moal MC, et al; RAD A2420 Study Group Incidence of delayed graft function and wound healing complications after deceased-donor kidney transplantation is not affected by de novo everolimus. Transplantation. 2009;88(1):69-76.

33. Langer RM, Hené R, Vitko S, et al. Everolimus plus early tacrolimus minimization: a phase III, randomized, open-label, multicentre trial in renal transplantation. Transpl Int. 2012;25(5):592-602.

34. Cibrik D, Silva HT, Vathsala A, et al. Randomized trial of everolimusfacilitated calcineurin-inhibitor minimization over 24 months in renal transplantation. Transplantation. 2013;95(7):933-942.

35. Zeier M, van der Giet M. Calcineurin inhibitor sparing regimens using m-target of rapamycin inhibitors: an opportunity to improve cardiovascular risk following kidney transplantation. Transpl Int. 2011;24(1): 30-42.

36. Gao XM, Wong G, Wang B, et al. Inhibition of mTOR reduces chronic pressure-overload cardiac hypertrophy and fibrosis. J Hypertens. 2006;24(8):1663-1670.

37. Buss SJ, Muenz S, Riffel JH, et al. Beneficial effects of mammalian target of rapamycin inhibition on left ventricular remodeling after myocardial infarction. J Am Coll Cardiol. 2009;54(35):2435-2446.

38. Paoletti E, Amidone M, Cassottana P, Gherzi M, Marsano L, Cannella G Effect of sirolimus on left ventricular hypertrophy in kidney transplant recipients: a 1-year nonrandomized controlled trial. Am J Kidney Dis. 2008;52(2):324-330.

39. Murbraech K, Holdaas H, Massey R, Undset LH, Aakhus S. Cardiac response to early conversion from calcineurin inhibitor to everolimus in renal transplant recipients: an echocardiographic substudy of the randomized controlled CENTRAL trial. Transplantation. 2014;97(3): 184-188.

40. Mueller MA, Beutner F, Teupser D, Ceglarek U, Thiery J. Prevention of atherosclerosis by the mTOR inhibitor everolimus in LDLR -/- mice despite severe hypercholesterolemia. Atherosclerosis. 2008;98(1): 39-48.

41. Eisen HJ, Kobashigawa J, Starling RC, et al. Everolimus versus mycophenolate mofetil in heart transplantation: a randomized, multicenter trial. Am J Transplant. 2013;13(15):1203-1216.

42. Eisen HJ, Tuzcu EM, Dorent R, et al; RAD B253 Study Group. Everolimus for the prevention of allograft rejection and vasculopathy in cardiac-transplant recipients. $N$ Engl J Med. 2003;349(9):847-858.

43. Seckinger J, Sommerer C, Hinkel UP, Hoffmann O, Zeier M, Schwenger V. Switch of immunosuppression from cyclosporine A to everolimus: impact on pulse wave velocity in stable de-novo renal allograft recipients. J Hypertens. 2008;26(11):2213-2219.

44. Joannidès R, Monteil C, de Ligny BH, et al. Immunosuppressant regimen based on sirolimus decreases aortic stiffness in renal transplant recipients in comparison to cyclosporine. Am JTransplant. 2011;11(11): 2414-2422.
45. Claes KJ, Heye S, Bammens B, et al. Aortic calcifications and arterial stiffness as predictors or cardiovascular events in incident renal transplant patients. Transpl Int. 2013;26(10):973-981.

46. Opelz G, Döhler B. Association of HLA mismatch with death with a functioning graft after kidney transplantation: a collaborative transplant study report. Am J Transplant. 2012;12(11):3031-3038.

47. Opelz G, Döhler B. Association between steroid dosage and death with a functioning graft after kidney transplantation. Am J Transplant. 2013;13(8):2096-2105.

48. Gutiérrez-Dalmau A, Campistol JM. The role of proliferation signal inhibitors in post-transplant malignancies. Nephrol Dial Transplant. 2007;22 Suppl 1:i11-i16.

49. Motzer RJ, Escudier B, Oudard S, et al; RECORD-1 Study Group. Efficacy of everolimus in advanced renal cell carcinoma: a double-blind, randomized, placebo-controlled phase III trial. Lancet. 2008;372(9637): $449-456$.

50. Campbell SB, Walker R, Tai SS, Jiang Q, Russ GR. Randomized controlled trial of sirolimus for renal transplant recipients at high risk for nonmelanoma skin cancer. Am J Transplant. 2012;12(5):1146-1156.

51. Euvrard S, Boissonnat P, Roussoulières A, et al. Effect of everolimus on skin cancers in calcineurin inhibitor-treated heart transplant recipients. Transpl Int. 2010;23(8):855-857.

52. Tapiawala SN, Tinckam KJ, Cardella CJ, et al. Delayed graft function and the risk of death with a functioning graft. JAm Soc Nephrol. 2010;21(1): 153-161.

53. Egli A, Binggeli S, Bodaghi S, et al. Cytomegalovirus and polyomavirus BK posttransplant. Nephrol Dial Transplant. 2007;22 Suppl 8: viii72-viii82.

54. Brennan DC, Legendre C, Patel D, et al. Cytomegalovirus incidence between everolimus versus mycophenolate in de novo renal transplants: pooled analysis of three clinical trials. Am J Transplant. 2011;11(11): 2453-2462.

55. Suwelack B, Malyar V, Koch M, Sester M, Sommerer C. The influence of immunosuppressive agents on BK virus risk following kidney transplantation, and implications for choice of regimen. Transplant Rev (Orlando). 2012;26(3):201-211.

56. Gurk-Turner C, Manitpisitkul W, Cooper M. A comprehensive review of everolimus clinical reports: a new mammalian target of rapamycin inhibitor. Transplantation. 2012;94(7):659-668.

57. Junge G, Bernhardt P, Escrig C, Tedesco Silva H. Surrogate renal endpoints for predicting long-term allograft survival in kidney transplantation. Abstract SA-PO1008 presented at American Society of Nephrology Kidney Week, Atlanta, GA, USA, November 5-10, 2013.

58. Srinivas TR, Flechner SM, Poggio ED, et al. Glomerular filtration rate slopes have significantly improved among renal transplants in the United States. Transplantation. 2010;90(12):1499-1505.

59. Tanaka T, Kyo M, Kokado Y, et al. Correlation between the Banff 97 classification of renal allograft biopsies and clinical outcome. Transpl Int. 2004;17(2):59-64.

60. Banas B, Albano L, Cassuto E, et al; On behalf of the OSAKA Study Group. The impact of acute rejection on renal function - perspectives from the OSAKA study. Transplantation. 2012;94(10S):983.

61. Haas M, Kraus ES, Samaniego-Picota M, Racusen LC, Ni W, Eustace JA. Acute renal allograft rejection with intimal arteritis: Histologic predictors of response to therapy and graft survival. Kidney Int. 2002;61(4):1516-1526.

62. Sis B, Mengel M, Haas M, et al. Banff '09 meeting report: antibody mediated graft deterioration and implementation of Banff working groups. Am J Transplant. 2010;10(3):464-471.

63. Kovarik JM, Curtis JJ, Hricik DE, Pescovitz MD, Scantlebury V, Vasquez A. Differential pharmacokinetic interaction of tacrolimus and cyclosporine on everolimus. Transplant Proc. 2006;38(10): 3456-3458. 


\section{Publish your work in this journal}

The Open Access Journal of Clinical Trials is an international, peerreviewed, open access journal publishing original research, reports, editorials, reviews and commentaries on all aspects of clinical trial design, management, legal, ethical and regulatory issues, case record form design, data collection, quality assurance and data auditing

Submit your manuscript here: http://www.dovepress.com/open-access-journal-of-clinical-trials-journal methodologies. The manuscript management system is completely online and includes a very quick and fair peer-review system, which is all easy to use. Visit http://www.dovepress.com/testimonials.php to read real quotes from published authors. 